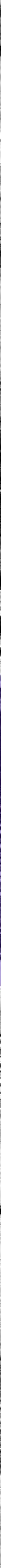




\section{[MÔNICA NEDER]}

Professora no Instituto de Artes e Design da Universidade Federal de Juiz de Fora.

\section{E-mail: monicaneder@gmail.com}

[resumo] Este artigo trata do monitoramento de cor realizado durante as semanas de moda do Rio de Janeiro e de São Paulo no período de 2013 a 2016. 0 objetivo era perceber congruências de cores nos lançamentos. Para tanto, foi feito um estudo bibliográfico sobre tendências e pesquisas de moda, além de coleta das cores. Devido ao alto poder de disseminação da informação na rede, as informações analisadas foram coletadas na internet. Para o registro dos dados, construímos mapas de cores que, posteriormente, foram analisados por meio de fichas visuais e escritas. Para o entendimento da repetição dos padrões coloridos ao longo do período abrangido pelo estudo, produzimos gráficos comparativos categorizados por família, luminosidade e saturação.

\section{palavras-chave}

\section{monitoramento; moda; tendências; cor.}

[abstract] This article is a register of the color monitoring fulfilled during the fashion weeks in Rio de Janeiro and São Paulo from 2013 to 2016. The main purpose was the search for patterns of color repetition. Therefore, it was accomplished a bibliographical study about trends and fashion research, in addition to a field survey for collection of sample. Due to its high power of information dissemination, the chosen instrument was the digital environment, using the internet. To record the samples, we built color maps, which were subsequently analyzed by means of visual and written records. In order to understand the repetition of colorful patterns over the period covered by the study, there were built comparative graphs categorized by family, brightness and saturation.

[keywords] monitoring, fashion; trends; color. 


\section{Introdução}

Entende-se que o consumo de moda pertence a um cenário em constante mutação, sem variações radicais, que forma um fluxo contínuo de informações sobre cores, formas e matérias-primas. Tais alterações são consequência dessa fluidez cuja significação social comunica e mantém as relações humanas. Posto isso, corroboramos com Douglas e Isherwood (2010) ao afirmarem serem os bens marcos sinalizadores das decisões de consumo e, logo, da cultura do momento. Para um melhor acompanhamento dessa transformação gradual no consumo, é fundamental que haja uma constante atualização sobre o comportamento consumidor durante o processo de criação e a construção da roupa e a sua comercialização, evitando inadequações em relação às novas sugestões de vestuário para os diferentes segmentos. As marcas e os fabricantes de roupas, tecidos e pigmentos consideram de notável importância a informação ao planejar investimentos, desenvolvimentos e aquisições de produtos e tecnologias que contribuam para a primazia competitiva no mercado.

Os lançamentos de produtos pelas marcas e pelos criadores contribuem para a efemeridade na moda. A cada edição, desfiles, editoriais e publicidades encontram no meio digital importantes recursos para a disseminação das propostas apresentadas.

Com o intuito de compreender continuadamente quais são os caminhos viáveis para a criação e o desenvolvimento de novos produtos de moda, há uma série de pesquisas acadêmicas e de mercado. Como referência, citamos a do ProCor do Brasil, representante na Association Internationale de la Couleur (AIC), a do Comitê Brasileiro de Cores/CECAL - Centro de Estudos de Cor para a América Latina e a feita anualmente pela Pantone ${ }^{\circledR}$, uma das maiores prestadoras de serviços para a indústria criativa e o varejo, que atende diferentes áreas, tais como moda, design e arquitetura.

Para o monitoramento de cor proposto, focamos a pesquisa nos principais eventos de moda no Brasil: o São Paulo Fashion Week (SP) e o Fashion Rio (RJ), até 2016. A motivação para essas escolhas foi o grande volume de negócios e informações que acontecem a cada edição, além da enorme circulação de pessoas. Na expectativa da repercussão dos lançamentos, encontramos consumidores e cadeia produtiva interessados pelas análises dos especialistas sobre o que dará certo ou errado no consumo de moda.

Nas semanas de moda brasileiras em destaque, observou-se uma grande diversidade de informações e, por conseguinte, tomamos como premissa 
desta pesquisa a análise das cores responsáveis por atrair o olhar e conquistar o interesse do consumidor/navegador da internet. Como recorte, no âmbito do consumo de vestuário, selecionamos o segmento feminino. No Brasil, segundo pesquisa da Fundação Getúlio Vargas do Rio de Janeiro publicada em 2015, as mulheres lideram as compras do setor de artigos têxteis com $45 \%$ das aquisições de roupas, por isso, as cores utilizadas nos lançamentos são de interesse da grande parte dos especialistas e fabricantes de roupas e matérias-primas desse segmento. 0 objeto de estudo da pesquisa - o segmento feminino - atrai a maior atenção da mídia e, por esse motivo, temos como objetivo perceber a existência ou não de afluência das cores a cada lançamento.

\section{Justificativa}

0 uso das cores é tratado como um dos principais direcionadores de tendências de moda nas referências de birôs de estilo, fabricantes de fibras e de tecidos. Ao observar e acompanhar as cartelas, não foi possivel perceber 0 método empregado para defini-las. São poucas as referências sobre o assunto e, quando aparecem, são tratadas de forma ambígua, talvez com o objetivo de manter-se algum sigilo, pois as empresas de pesquisa que comercializam os resultados assumem um cuidado na preservação de seus métodos de trabalho.

Nesse desenho de cenário, entendemos que é importante o estudo, a observação, a dedução e o registro do material publicado pelos birôs, para adaptar à realidade das empresas e aos seus mercados de atuação as criações lançadas periodicamente em desfiles, catálogos e editoriais de moda.

As indagações iniciais que surgiram a partir deste projeto caracterizaram a pesquisa como qualitativa e de natureza aplicada. Os objetivos giraram em torno de uma abordagem exploratória em razão da sondagem realizada acerca do tema no campo de pesquisa brasileiro. Os procedimentos técnicos têm cunho bibliográfico e documental.

Na busca de convergência das cores nos lançamentos de moda foi feito um monitoramento dos desfiles na internet. 0 principal método utilizado tem como base a observação e a coleta manual das cores predominantes das vestimentas exibidas em todas as imagens dos desfiles nas semanas de moda na cidade de São Paulo (São Paulo Fashion Week) e no Rio de Janeiro (Fashion Rio) durante quatro anos. Elas estão disponibilizadas no site www.ffw.com.br, da empresa Luminosidade, organizadora dos eventos, pertencente ao Grupo InBrands e associada ao Grupo ABC.

Como fundamentação teórica, recorremos a Bauer (2008) e a Caldas (2004) na verificação de diferentes métodos utilizados na área de pesquisa de moda; a Santos (2013) e Rheingantz et al (2009) para a comparação de métodos de pesquisa qualitativas; a Lambert (1991) para o estudo das caracteristicas das cores e a sua construção; e a Douglas e Isherwood (2004) como referência nos estudos de comportamento do consumidor. 


\section{Tendências e comportamento do consumidor}

Em um cenário dinâmico, hibrido e codificado como o contemporâneo, a pesquisa de tendências para a criação de vestimentas foi intensificada e evoluiu para uma diversificação dos meios (impressos e digitais) e métodos, variando conforme as empresas e as marcas. Caldas (2004) menciona que o fato de se apontar uma direção na moda não significa que ela será concretizada. Acreditamos que isso aconteça tanto por causa da identificação do consumidor com a sedução montada pelo estilista quanto pela influência de pessoas conhecidas do público em suas aparições na mídia e até mesmo como personagens de novelas televisivas. Percebemos que celebridades possuem admiradores que se identificam com a sua aparência e querem se assemelhar a elas a partir da escolha de suas roupas. Isso contribui com a mutação que uma tendência pode sofrer por estar ligada ao futuro, ou ainda pode sofrer interferências de variáveis incontroláveis. Segundo o autor, a incerteza da previsão é acentuada diante da complexidade do comportamento do consumidor e dos meandros da cadeia produtiva têxtil.

A tendência é algo que aponta a direção do que poderá acontecer, por isso, não podemos considerá-la como infalivel e certa. A sua pesquisa tem, em um âmbito maior, a função de identificar situações e temas globais que forneçam dados mais duradouros para a compreensão da diversidade dos cenários de projeto. Caldas (2004) afirma que ela abarca aspectos políticos, econômicos, sociais, culturais e ambientais - as chamadas macrotendências ou tendências de fundo - com o intuito de dar parâmetros para a pesquisa de cor (na identificação das microtendências), tendo em vista a estruturação da sazonalidade na moda e, portanto, de sua curta duração. É nesse âmbito que a maioria das empresas e dos criadores trabalha e são pressionados a apresentarem novidades constantemente, quando o público está motivado para o consumo.

Como um método de pesquisa que contribui para a comunicação da informação de moda, Santos (2013) menciona a importância da análise de conteúdo, "proveniente do monitoramento dos meios de comunicação e notícias do que acontece global e localmente" (SANTOS, 2013, p. 72). Uma forma muito utilizada nesse tipo de monitoramento é o coolhunting. Este é um método de pesquisa de campo que identifica manifestações, atitudes, hábitos e sinais repetidos, assinalando as tendências do momento. Esses sinais são "sintomas que se repetem, permanecem, diagnosticam um estado de sociedade" (SANTOS, 2013, p. 73). Em relação à comunicação das ideias, analisam-se, nas diferentes mídias, as notícias relativas à moda, ao design, às artes, à arquitetura e à cultura nos âmbitos local, regional, nacional e internacional. Geralmente, as empresas que fazem pesquisa de moda utilizam o coolhunter com um perfil muito próximo do consumidor que desejam investigar. Dessa forma, consegue-se um mimetismo com o ambiente, monitorando o que poderia passar despercebido por um pesquisador estranho ao campo observado.

Segundo Neder (2013), as empresas utilizam como método de pesquisa uma mistura de instrumentos que variam conforme o objetivo, o orçamento e o tempo disponivel. A autora coloca como exemplos de ferramentas utilizadas 
sites de marcas internacionais, publicações especializadas em tendências de moda, feiras de fios, fibras e tecidos e revistas especializadas nas áreas de atuação das empresas, além do auxílio de coolhunters como complemento ao conteúdo divulgado pelos birôs e aos relatórios de escritórios de consultoria. Todos os exemplos supracitados, assim como outros complementares, proporcionam direcionamentos aos criadores que apresentam suas propostas baseadas em conceitos fundamentados pela análise do material resultante da pesquisa de moda.

\section{A pesquisa de cor}

A definição de uma cartela de cores envolve diferentes aspectos. É reconhecido que a produção do estilista nasce de um conceito na sua mente criadora e flui para a experimentação em formas e tecidos, mas o que também influencia essa experiência é o que os fornecedores de matéria-prima e insumos têm para oferecer e como eles podem contribuir com a criação. Muitos deles fazem parcerias para o desenvolvimento de novos substratos, misturas de fios e fibras, acabamentos, estampas e colorações. A cada estação do ano, surgem novas tonalidades e novos conceitos. As pesquisas e o desenvolvimento de produtos dos fabricantes de fibras, fios e tecidos são intercambiados com os criadores de vestimentas e acessórios de moda para a troca de conhecimentos e informações.

0 início - se existe tal início - do processo de pesquisa está muito antes do lançamento de uma coleção de vestimentas. Ele permanece em constante atualização, no monitoramento das macrotendências. É importante, ao longo do processo de estudos e observações, ampliar o olhar para outras áreas a fim de evitar uma limitação nas referências apenas sobre moda. Nessa pesquisa horizontal, áreas como design de interiores e de produtos e as artes visuais fazem parte de um sistema de valores que influenciam a moda e por ela são influenciados. Isto posto, podemos identificar vetores que apontam para um mesmo sentido formando um campo estético comum. Como exemplo, citamos os fabricantes de tecidos para o lar e os de papéis de parede que, cada vez mais, se aproximam do vestuário, formando por vezes parcerias com os criadores de moda. A experiência da estilista inglesa Vivienne Westwood nos serve de aprendizado: ela lançou uma coleção de papel de parede com desenhos históricos de sua autoria, que incluiu a estampa Squiggle, do início dos anos 1980.

Os lançamentos e a movimentação que estes provocam em todos os envolvidos com a moda não poderiam ser ignorados como uma possivel análise da fluidez representativa da cultura contemporânea. Diante da diversidade das informações levantadas nos eventos observados nesta pesquisa, focamos, em um primeiro momento, nas caracteristicas colorificas de uma vestimenta, que são exploradas nas criações a fim de conquistar o interesse do consumidor. Acreditamos que as cores mudam para reforçar o sentido alterável do objeto de moda como uma estratégia para estimular a morte das coisas a cada estação, justificando, assim, uma nova aquisição, como afirma Baudrillard (2012). Com isso, defendemos a ênfase dada às cartelas lançadas pelos 
filatórios e tecelagens, pelos birôs de tendências e em revistas especializadas, como a inglesa View on Color. Levamos em consideração, também, as cores assinaladas a cada ano pela Pantone ${ }^{\circledR}$, pois despertam interesses no público quando associadas às marcas de cosméticos e celebridades internacionais que, incentivadas, usam a tonalidade do momento.

Atualmente, a informação sobre tendências de cores está acessivel em sites como o http://www.fashiontrendsetter.com e em feiras nacionais e internacionais, como a Première Vision e Expofil. Quando as empresas necessitam de informações mais aprofundadas e pontuais sobre seus respectivos mercados, contratam consultorias que emitem relatórios ou trends reports. Mas, mesmo nesses casos, a assertividade nas vendas não está garantida. As fontes para uma pesquisa de moda são variadas e muitas empresas não observam convergências de cores nos lançamentos internacionais e nacionais. Detectamos, nesse quadro, a oportunidade de estudar cartelas de cores em diferentes lançamentos nacionais a fim de entender como as cores vêm e vão nas diversas edições.

Para identificar convergências nos lançamentos de moda no Brasil, objetivo desta pesquisa, foi feito um monitoramento dos desfiles nos dois principais eventos do setor. Nesse contexto, reconhecemos as cores como parte integrante das tendências de moda, cobrindo diferentes períodos. Além dos desfiles dos criadores nacionais e internacionais, a observação dos editoriais de moda em revistas e jornais foi importante para a verificação da assertividade das propostas.

\section{Monitoramento de cores}

0 monitoramento de cores feito por meio da internet a partir dos registros dos desfiles de moda, escolhido como fonte de referência sem versão impressa, traz limitações em seu formato, mas, como contrapartida, é um meio com o maior poder de disseminação da informação. As desvantagens durante $o$ trabalho de pesquisa surgiram devido às diferenças na calibração de monitores em computadores de mesa e portátil. Isso provocou distorções de tonalidades, saturação e luminosidade. Destarte, a precisão na definição dos sistemas de ordenação de cores tornaria inviável o trabalho, pois seria impossivel o acesso a todas as vestimentas das temporadas focadas pelo estudo. No início, isso foi um obstáculo quase intransponível, mas o empenho em registrar e entender a representação das cartelas de cores na criação de moda no período estipulado motivou a busca de uma solução. Sem a preocupação com a precisão da construção da cor e mais interessados na atração que as imagens exercem na percepção do navegador e do leitor casual, do curioso em moda e dos especialistas que acompanham os lançamentos à distância, os parâmetros de quente e frio foram as principais escolhas para esta pesquisa.

A fim de corroborar com a designação do campo digital na pesquisa, observamos que os métodos utilizados na prospecção das cores a cada 
estação sofreram mudanças significativas em comparação com os do fim do século XX. De dispendiosas viagens internacionais a elaborados birôs (NEDER, 2016), as empresas e os criadores ganharam com a internet novas fontes de informação, pagas e gratuitas, que variam conforme a profundidade do conteúdo ofertado.

Baudrillard (2012), Goethe (1993) e Kandisky (1996) fundamentaram nossa abordagem com suas definições emocionais sobre cores. Como complemento, mas sem menos importância, o branco, o preto e o cinza ganharam destaque devido ao grande número de aparições e por serem consideradas cores básicas e neutras por muitos fabricantes de tecidos e vestimentas.

Diante dessa decisão, a melhor forma de segmentar as cores coletadas foi parti-las em três grupos distintos, neutras, quentes e frias. Essa estrutura facilitou a definição do lugar de cada cor, apesar das distorções do meio digital. As imagens dos desfiles, importantes faróis do consumo de moda, são o referencial desse monitoramento e ilustram a recorrência das cores, como uma sintese. Partimos do princípio de que quando uma tonalidade aparece mais do que outra, detectamos uma congruência que contribui para a delimitação de uma tendência forte ou um vetor para uma determinada coloração ser mais ofertada.

Acreditamos que, independentemente das cartelas apresentadas pelos fornecedores, as empresas são soberanas em suas criações. No processo criativo, a aplicação da cor é livre e os estilistas utilizam as cartelas mais apropriadas ao conceito das coleções, que estão em sintonia com o design e as artes visuais, inspiradores para combinações inusitadas nos tecidos. Eles veem o consumidor como um novo protagonista criativo, que se expressa por meio do que veste, sinalizando o seu comportamento. Esse fato demandou dos estilistas um percurso criativo distinto do que vinha sendo praticado até então.

0 meio digital contribuiu para um acesso amplo à informação e, por meio dele, as tendências são disseminadas rapidamente para as pessoas interessadas na área, consumidores ou fabricantes de vestimentas. Além das informações serem distribuídas quase instantaneamente aos seus lançamentos, houve uma notável redução de custos nas pesquisas, contribuindo para o surgimento de novos formatos na consultoria de cor.

Para realizar o referido monitoramento, estruturamos três etapas metodológicas: observação, registro e análise. Essa disposição foi proposta para um melhor estudo das cartelas dos desfiles, dispostas em mapas de cores, segundo parâmetros predefinidos. Isso facilitou a identificação e a catalogação do material coletado sem comprometer o trabalho, levando em conta a infidelidade da cor no meio digital. 


\section{1ª etapa: observação}

Foram observados todos os desfiles tanto da cidade de São Paulo quanto do Rio de Janeiro no período previsto (2013 a 2016) para melhor entender a sequência das cores utilizadas. Essa etapa contribuiu para a identificação das cartelas utilizadas pelos criadores e suas marcas.

Apesar de estarmos sujeitas à imprecisão pelas possiveis alterações da cor provocadas pelo meio digital utilizado, contamos com essa fonte, já que também é uma propagadora das marcas e dos estilistas. Vale ressaltar que é um meio viável e gratuito e, por isso, muito utilizado por pessoas que se interessam por moda, consumidores ou profissionais da área.

\section{$2^{\text {a }}$ etapa: registro}

Para registrar e utilizar os resultados do monitoramento, delimitamos três grupos - neutras, quentes e frias -, cada um com aspectos simbólicos que contribuem para as escolhas. Primeiramente, tratamos a cor como uma força da criação, "proporcionando leituras diferenciadas em cada pessoa, conforme a percepção individual" (ARAÚJ0, 2006, p. 86). Com esse intuito, é importante entendê-la como um estímulo que a torna desejada. As cores funcionam como ícones relacionados às experiências psicológicas, culturais e sociais. A sua significação contribui para a construção de uma linguagem simbólica que provoca uma reação emocional traduzida pelo gostar ou não de algo. Assim, apontamos para um caminho de identificação grupal ou [243] individual perante as escolhas.

Para o melhor entendimento da delimitação dos três grupos organizacionais, buscamos base em Baudrillard (2012), quando ele discorre sobre cores quentes e frias, em como as quentes dão o sentido de intimidade e as frias fazem um contraponto: "Sendo o 'caloroso' continuamente adiado. É um calor significado e por isso mesmo não se realiza jamais" (BAUDRILLARD, 2012, p. 44). Concordamos com John Cohn que, no início dos anos 1890, definiu um instinto básico sensual das pessoas para as cores fortes, modificado apenas pela cultura. Amparamo-nos no psicólogo romeno Florian Stefanescu-Goanga (1881-1958) que, no mesmo laboratório de pesquisa de Cohn, afirmou que o azul é calmo, depressivo, pacífico, quieto, sério, nostálgico, melancólico, frio, calmo e sonhador. E, finalmente, estudamos a teoria dos efeitos das cores nas preferências individuais do psicólogo alemão Wilhelm Wundt, de 1900.

No início do século $X X$, pesquisadores avançaram na direção da sinestesia e da cromoterapia afirmando que a cor é mais uma questão de sentimento do que de julgamento intelectual, como propunha o americano Edwin Babbit (1828-1905). Por isso, acreditamos que a observação dos lançamentos de moda pela internet não pode ser desconsiderada devido à imprecisão na reprodução das cores. Mesmo que a princípio seja uma ilusão, as imagens percebidas nas telas dos computadores e dispositivos móveis são, para os observadores, uma verdade percebida. É como se a luz emitida das telas revelasse coisas que só poderiamos ver se lá estivéssemos. 
Esse principio incentivou, nesta pesquisa, a árdua coleta de 3 mil cores com o Photoshop ${ }^{\circledR}$, um software de tratamento de imagens. 0 registro foi feito por meio de mapas nos quais as tonalidades utilizadas por cada criador e cada marca foram segmentadas nos grupos anteriormente citados. Esses agrupamentos foram fundamentados na própria limitação do campo de estudo, o meio digital, pois possuem caracteristicas que permanecem reconhecidas por meio de monitores com diferentes calibragens. Além disso, como dito anteriormente, os aspectos simbólicos tiveram grande peso, pois acreditamos que influenciam as escolhas do observador que navega na internet.

Cores neutras: este grupo é composto de tonalidades brancas, cinzas e pretas. Para melhor definição e localização no mapa, estas cores foram comparadas com uma escala de cinza existente no software utilizado (Quadro 1).

Cores quentes: composto por tonalidades vermelhas, amarelas e laranjas.

Cores frias: composto por tonalidades azuis, verdes e violetas. Tanto este grupo quanto o das quentes tiveram como parâmetro a escala RGB (red, green, blue) do software utilizado (Quadro 1).

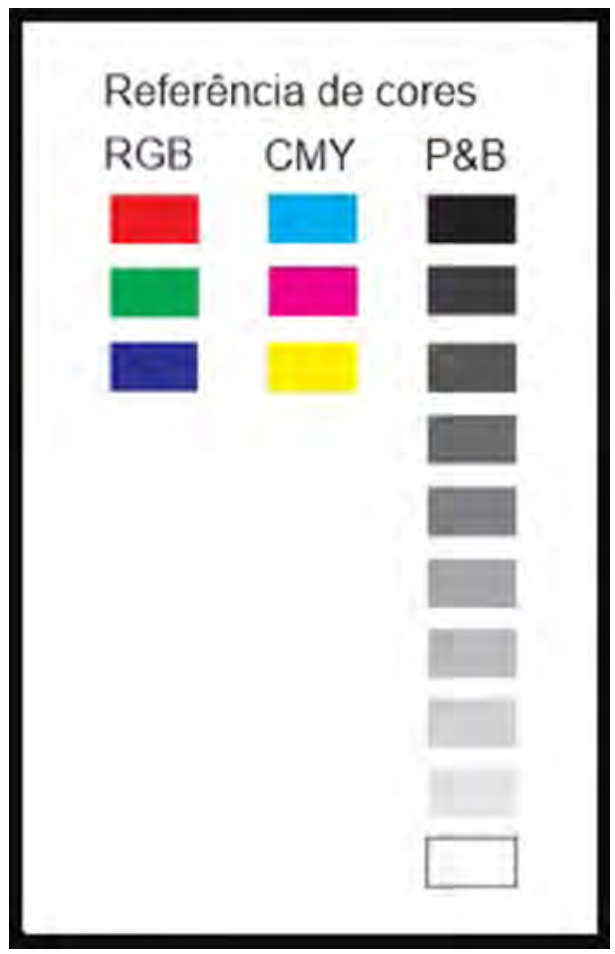

Quadro 1 - Referência de cores. Fonte: A autora.

Posteriormente, fez-se uma análise do mapa juntando todas as cartelas coletadas em cada ano, para a fim de se obter uma visualização geral e, dessa forma, determinar os vetores e as insistências da aparição das tonalidades. 0 registro da coleta de cores foi colocado no formato de uma tabela denominada Mapeamento (Figuras 1, 2 e 3). Elas foram alocadas em linhas horizontais, de acordo com cada criador e cada marca, por ordem de desfiles e suas respectivas escolhas de cartelas. As colunas foram categorizadas pelos grupos de cores neutras, quentes e frias. 
Evolução da cor na moda | SPFW INVERNO 2015

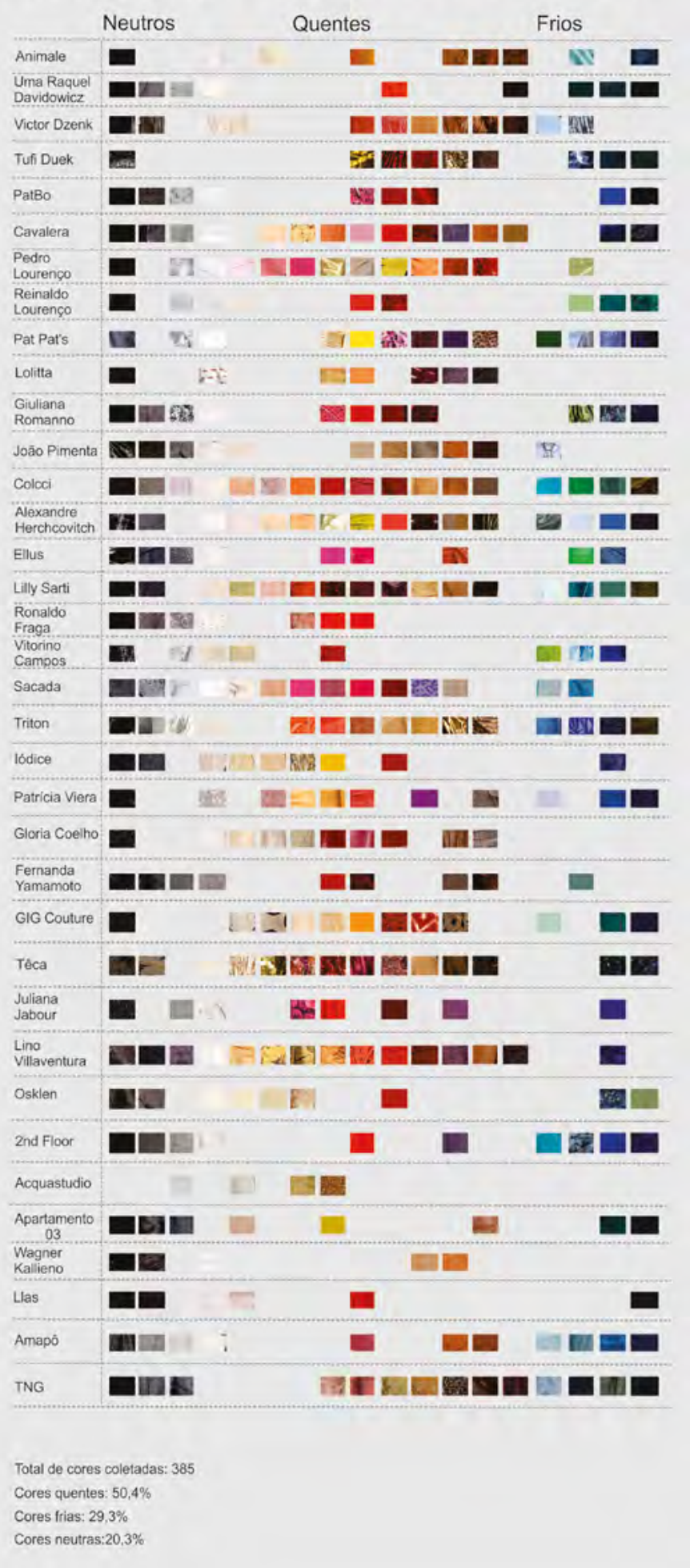

Figura 1 - Mapeamento do SPFW Inverno/2015. Fonte: A autora. 


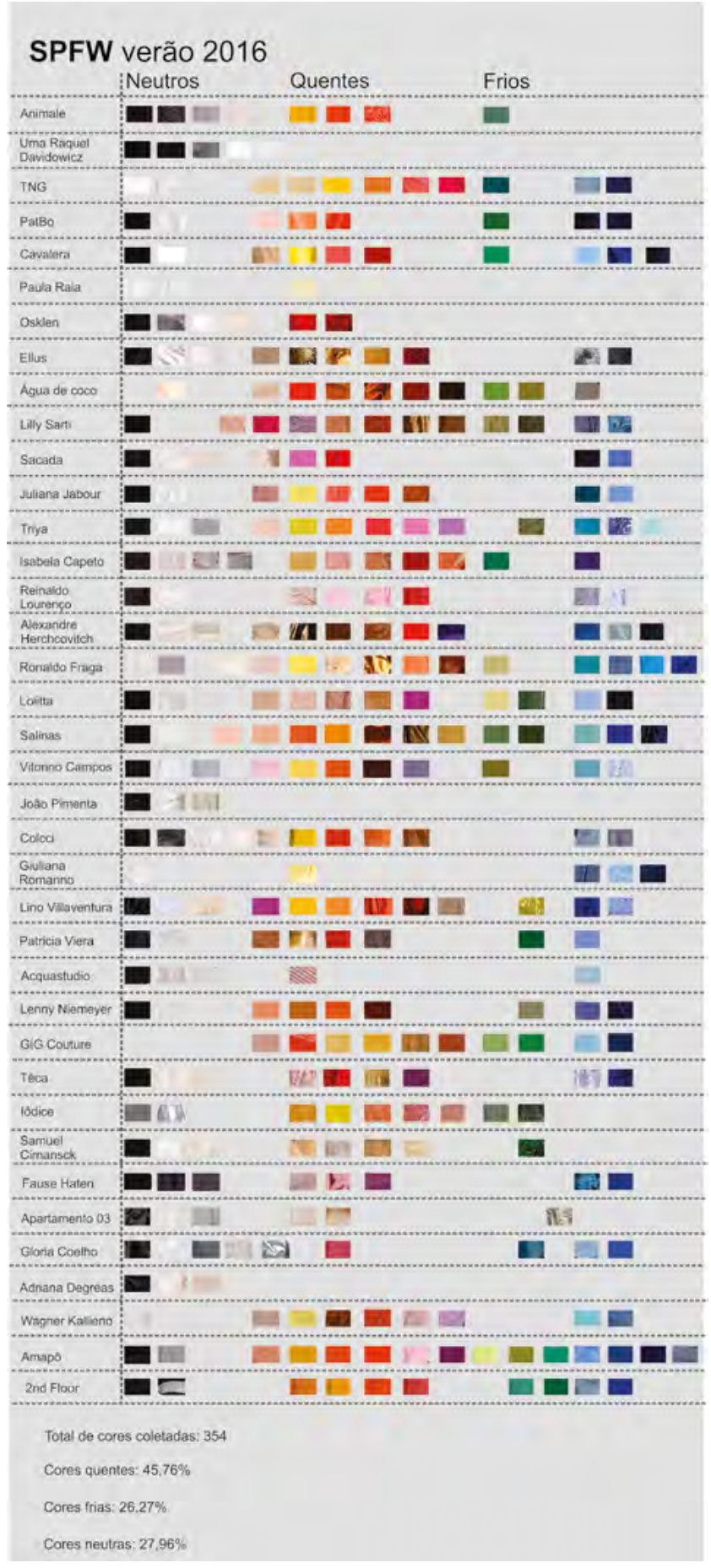

Figura 2 - Mapeamento do SPFW Verão/2016. Fonte: A autora. 


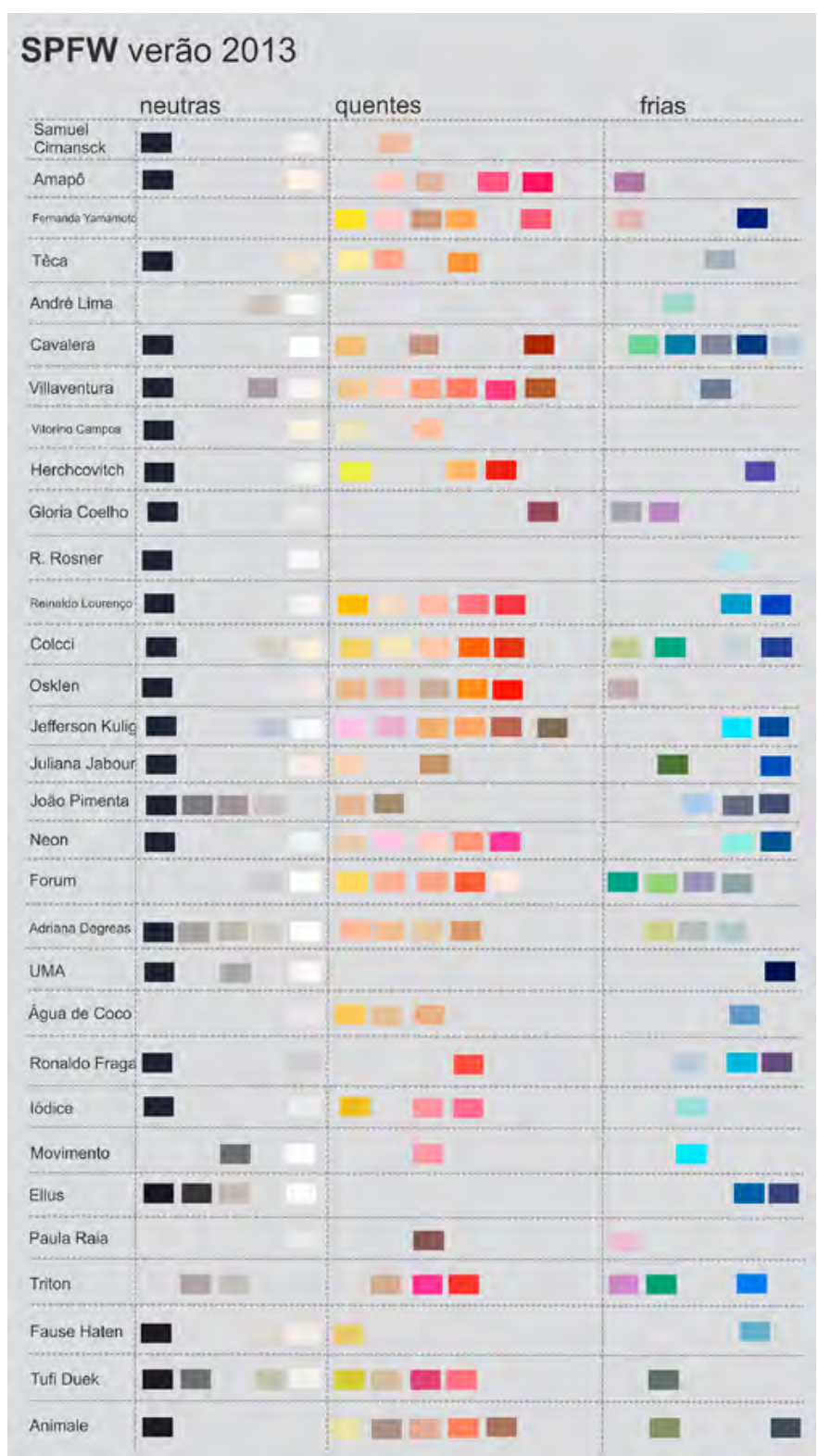

Figura 3 - Mapeamento do SPFW Verão/2013. Fonte: A autora.

\section{3a etapa: análise}

Nessa etapa, realizamos uma separação visual das cores de acordo com cada estação e fizemos uma análise escrita seguindo uma predefinição de classificação para garantir a objetividade do relato. A análise visual, em um primeiro momento, foi feita por meio de mapas de posicionamento (Figura 4) contendo todas as cores de uma mesma estação/ano, mostradas tanto no SPFW quanto no Fashion Rio. Neles, as cores coletadas foram separadas em grupos de vermelhas, amarelas, verdes, azuis e neutras; além de claras/escuras e quentes/frias.

Para categorizá-las com o máximo de precisão, criamos mapas de posicionamento (Figura 4) e neles localizamos as cores conforme os parâmetros de cores: 
Quentes: AM (amarelo) e VM (vermelho).

Frias: VD (verde) AZ (azul)

Luminosidade claro e escuro: branco, cinza e preto.

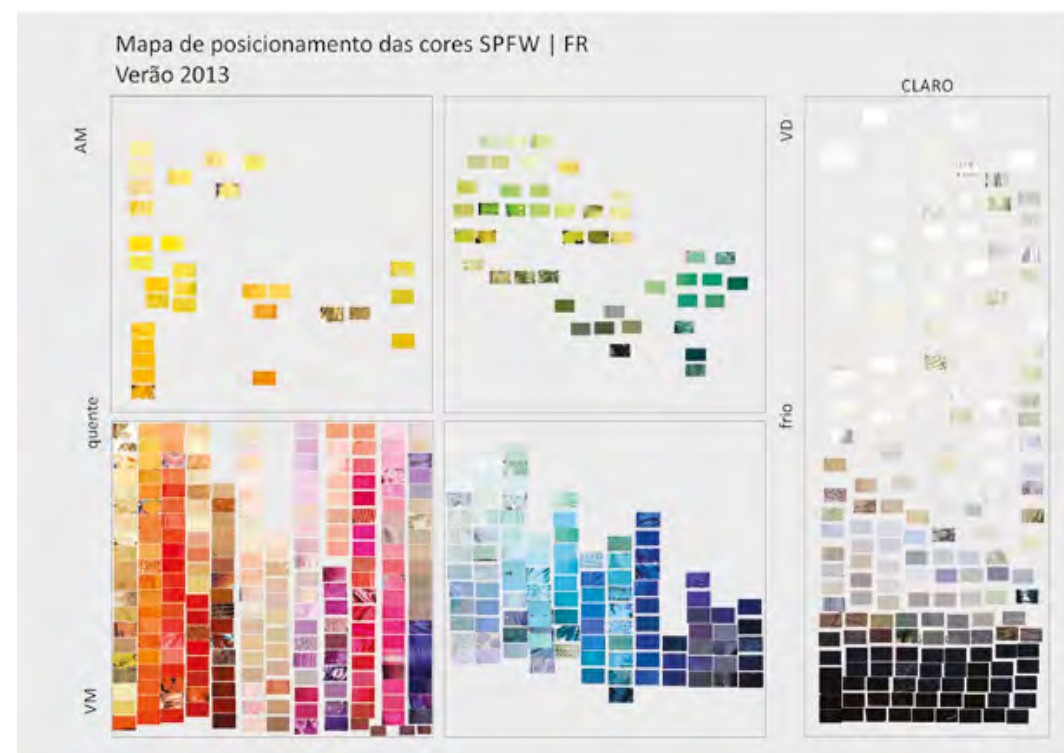

Figura 4 - Mapa de posicionamento SPFW/FR Verão/2013. Fonte: A autora.

Em um segundo momento, o resultado foi registrado em fichas de aná2/8 ] lise (Figura 5). Elas abrangeram questões sobre saturação, luminosidade, tonalidade e predomínio da família de cor. As fichas foram preenchidas após contagem das amostras para garantir a precisão nas ordenações crescentes e decrescentes. Com elas, foi possivel concluir quais as caracteristicas mais acentuadas para cada periodo de lançamento, além de definir a predominância da tonalidade que apontou um vetor definido como uma sintese de cor para cada estação.
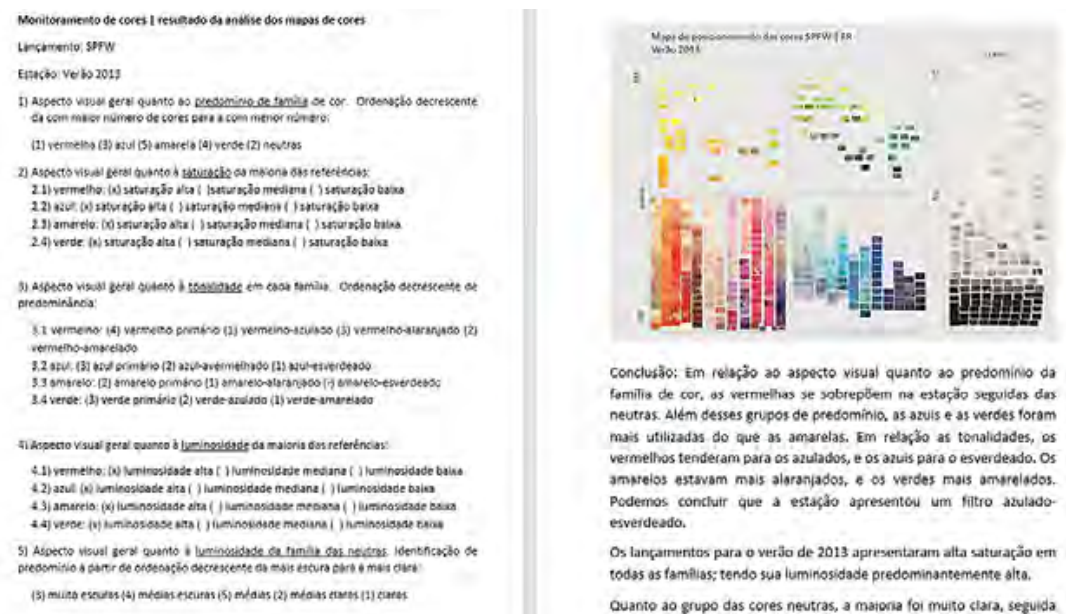

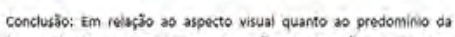
fomilia de cor, as vermelhas se sobreptern na estaçăo seguides das mass utilizadas do que as amarelas. Em relarto as tonalidates, os vermellinos tenderam para os azulados, e cos azuis para o e esverdeado. os

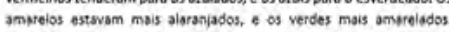
Podemos concluir que a estaj̧a apresentou um fittro azviado. esverdeado.

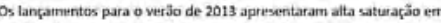
codas as famelias: tendo sia luminosidade predominantemente stro. Quanto ao grupo das cores neutras, a maiona for muto clara, seguida

Figura 5 - Análise escrita SPFW/FR Verão/2013. Fonte: A autora.

Ao todo, foram construidos 16 mapeamentos de cores; oito mapas de posicionamento e oito fichas de análise, além de quatro gráficos comparativos para a definição de congruências. 


\section{Resultados}

No decorrer do processo de coleta, organização e setorização das 3 mil amostras de cores, encontramos dificuldades devido à proximidade de algumas cores quanto à luminosidade e à saturação. Entretanto, foi notável o aprimoramento da percepção visual ao longo da elaboração de todos os mapas e gráficos.

Posteriormente, com todas as fichas em mãos, foram elaborados gráficos comparativos acerca dos aspectos referentes a cada estação no periodo de quatro anos. Desse modo, foi possivel perceber e compreender visualmente as variações e recorrências de uma série de caracteristicas utilizadas pelos estilistas nesse intervalo de tempo.

Para o predomínio de familia de cor, por exemplo, constatamos que, no inverno, existiu uma alternância ano a ano entre as tonalidades neutras e as avermelhadas e também entre as esverdeadas e as amareladas em menor proporção. As azuladas aparecem constantes na estação mais fria (Gráfico 1). É interessante a percepção de que quando as tonalidades avermelhadas estavam em alta, as amareladas estavam em baixa.

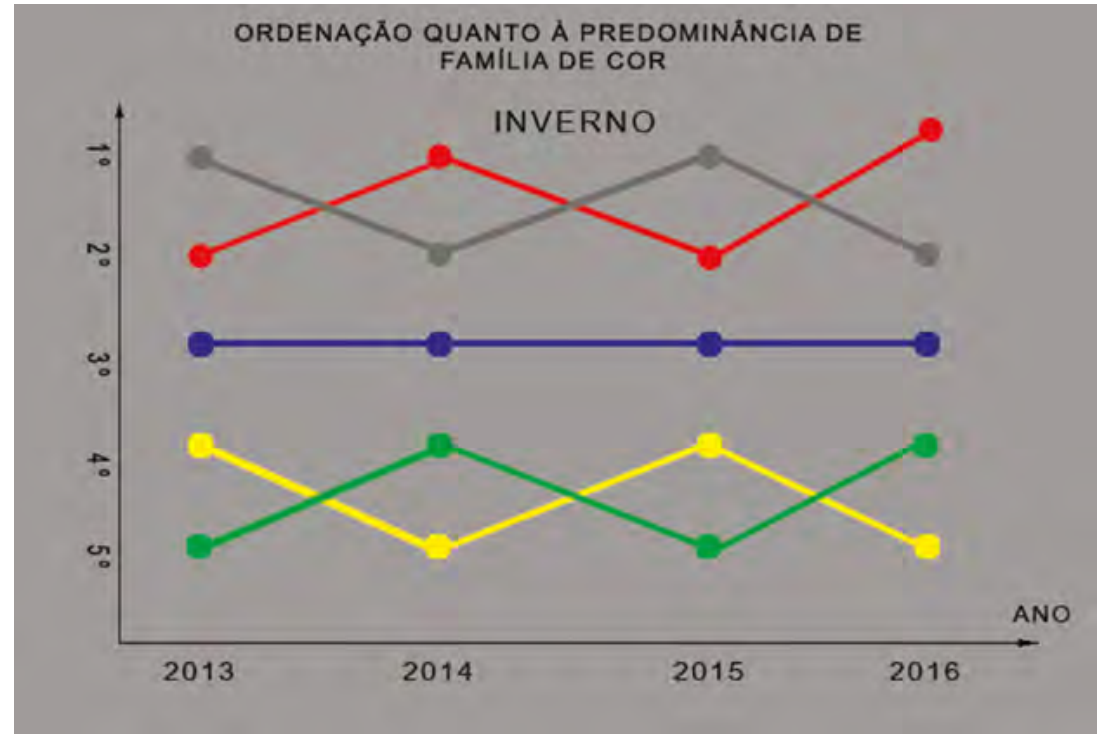

Gráfico 1 - Ordenação quanto à predominância da família de cor - Inverno.

Fonte: A autora.

No verão, as alternâncias são como no inverno: elas acontecem entre as neutras e as avermelhadas e entre as esverdeadas e as amareladas em menor proporção. Observamos que as azuladas permanecem constantes também na estação mais quente (Gráfico 2). 


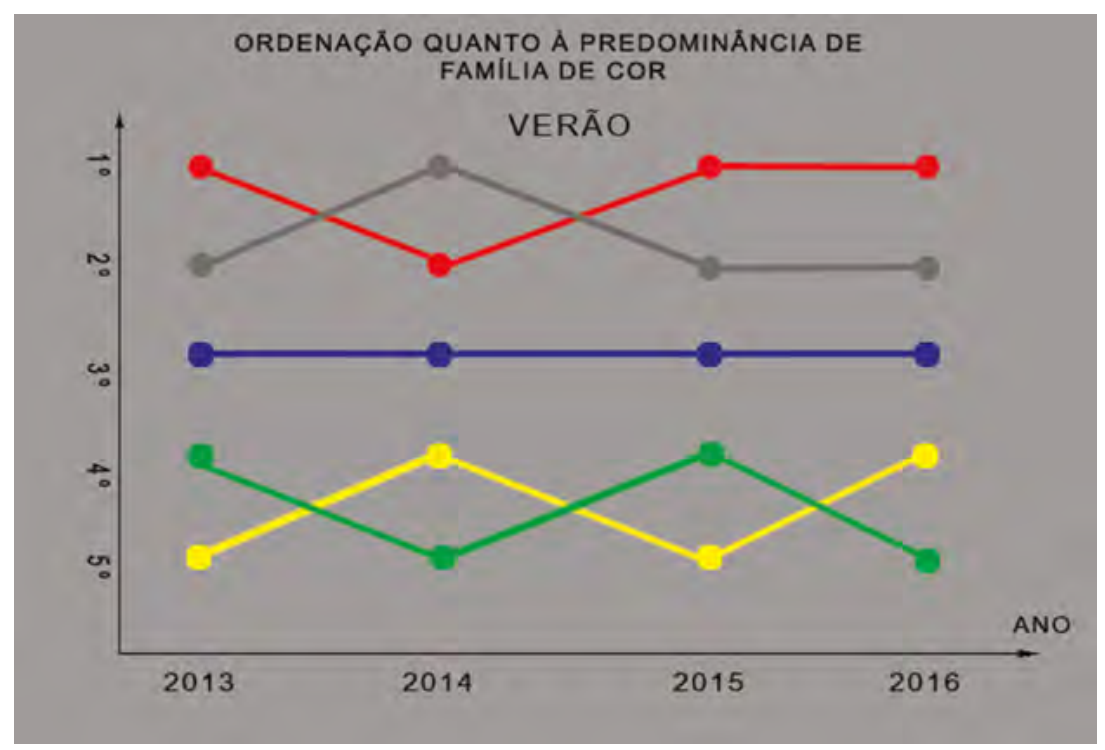

Gráfico 2 - Ordenação quanto à predominância da família de cor - Verão.

Fonte: A autora.

No inverno, em relação à luminosidade observada, as cores mais escuras foram predominantes, e as demais tonalidades das cores sofreram alterações sem percebermos recorrência ou padrão entre as escolhas dos criadores e marcas (Gráfico 3). A única exceção são as tonalidades vermelhas que, de 2014 a $25^{0}$ 2016, permaneceram constantes em sua luminosidade (cores claras ou escuras).

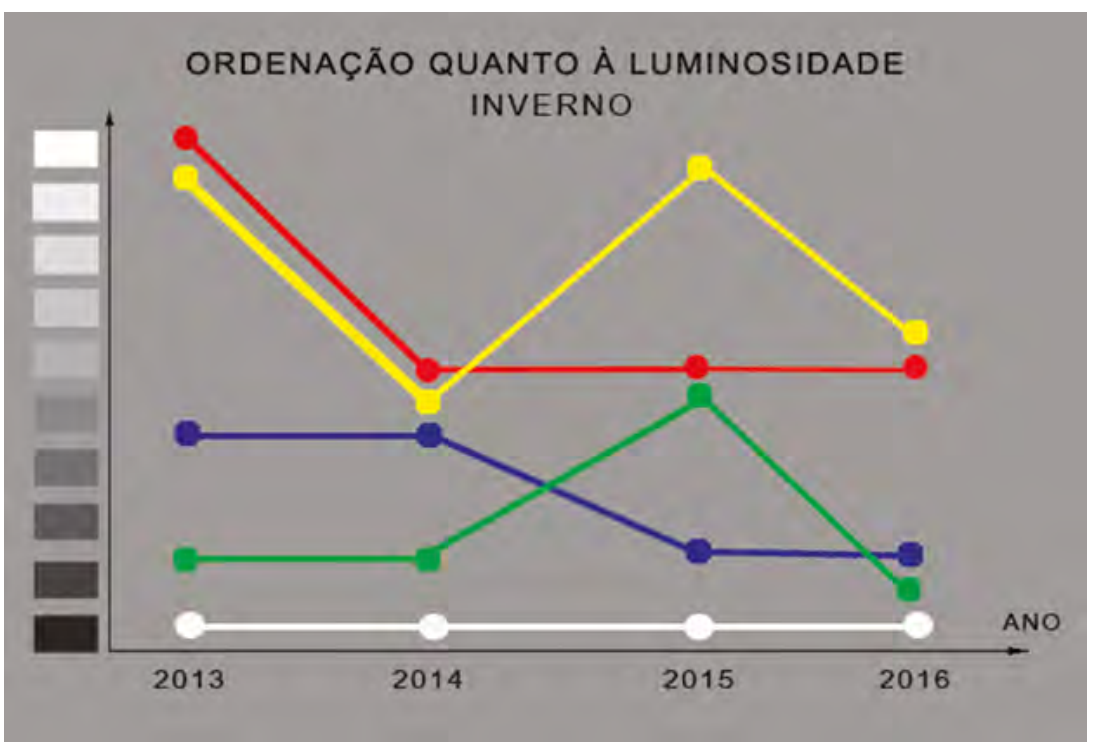

Gráfico 3 - Ordenação quanto à luminosidade - Inverno

Fonte: A autora.

No verão, a luminosidade foi mais constante ao longo dos anos, determinando uma recorrência. Percebemos que em 2013 e 2016, as tonalidades vermelhas, azuis e as cores neutras foram predominantemente claras. Em $2014 \mathrm{e}$ 2015, as cores vermelhas e azuis foram médias claras enquanto as amarelas e verdes foram médias escuras. Observamos, também, uma boa presença de preto (Gráfico 4). 


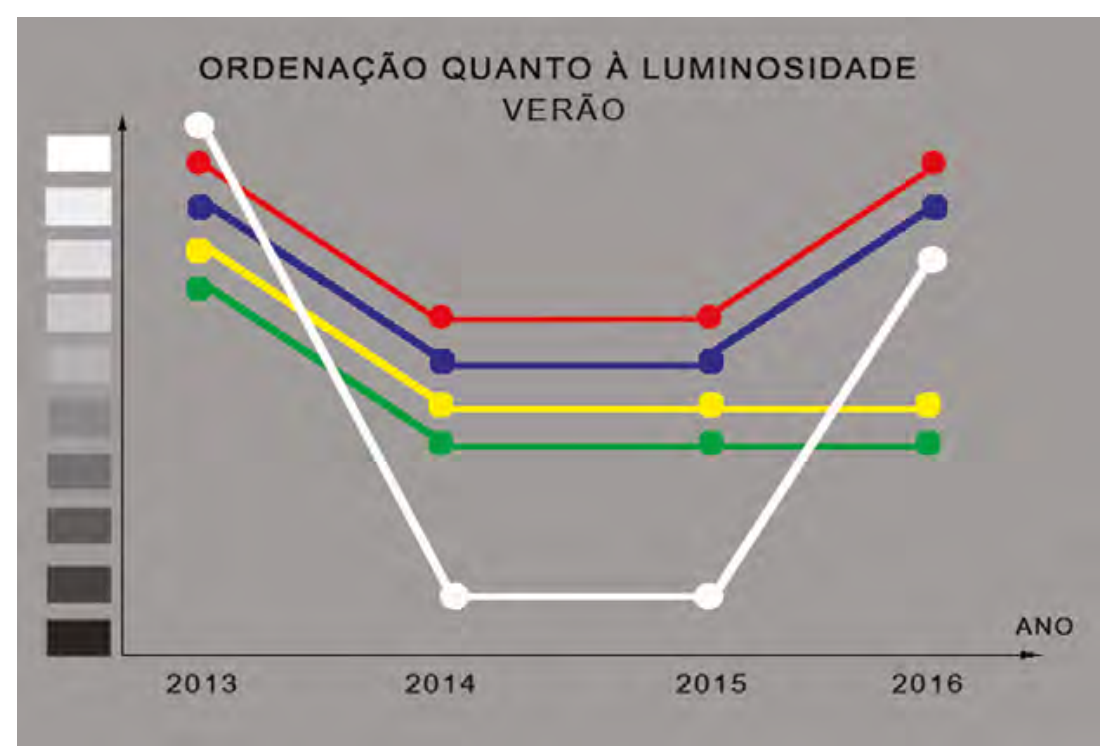

Gráfico 4 - Ordenação quanto à luminosidade - Verão

Fonte: A autora.

Ao analisar os gráficos, percebemos que as cores predominantes nos desfiles observados confirmam as impressões de que as cores escuras tendem a parecer em vestimentas próprias ao frio e as com mais luminosidade são recorrentes nas roupas leves das estações mais quentes. 0 mais interessante foi constatar a preferência pelos vermelhos nas criações de moda.

\section{$\left.25^{\mathbf{I}}\right] \quad$ Considerações finais}

As cores permitem uma mudança imediata na percepção da vestimenta e a possibilidade de tornar o objeto variável, incentivando o consumidor a uma constante atualização. Assim, acreditamos que a moda possibilita as transformações constantes no vestuário, conferindo à forma como nos vestimos uma comunicação sobre os modos ou as aspirações que explicitamos para outras pessoas.

No início da pesquisa documental, percebemos que as cores cedem lugar gradualmente umas às outras com a passagem das estações, em um ciclo de aproximadamente dois anos - com exceção do preto que predomina no inverno e as tonalidades vermelhas que sempre aparecem nas criações observadas. Distinguimos, nessa mudança, que algumas tonalidades retornam às escolhas dos criadores e das marcas, mostrando a preferência por uma ideia. Pesquisadores chineses, mais especificamente Li-Xia Chang (Jiangnan University), Wei Dong Gao (Henan Institute of Science and Technology) e Xin Zhang (Xi'an Polytechnic University), demonstraram que pesquisas feitas atualmente sobre cor são divididas em dois tipos: análise sistemática e dados históricos. Os autores supracitados demonstraram que, independentemente do método, corroboram com o curto prazo de dois anos na previsão de uma tendência de cor para a moda. Afirmam ainda que os dados históricos são uma importante fonte para a compreensão do conceito e a sensibilidade simbólica das cores em uma cartela e, por isso, devem ser levados em consideração nas pesquisas juntamente com as análises estatísticas de venda. 0 monitoramento tem um papel importante nos levantamentos de dados históricos, pois ele, além de 
registrar, contribui para o entendimento de como as cores aparecem e evoluem ao longo dos lançamentos de vestimentas. 0 resultado desta pesquisa nos levou à constatação de algumas convergências das cores nos lançamentos de moda. Registramos, no monitoramento, algumas congruências. São elas:

1. Quanto à predominância de família de cor, observamos uma forte presença das tonalidades avermelhadas tanto no inverno quanto no verão.

2. No inverno, a ênfase nas cartelas de cores lançadas pelos criadores é dada para as tonalidades neutras, com forte tendência para o preto.

3. Os tons azuis permanecem estáveis, isto é, com aparições constantes em todas as estações. Sem distinção de tonalidade quente ou fria.

4. Verdes e amarelos se alternam entre si, mas sempre em menor proporção se comparados aos tons neutros e avermelhados.

5. A luminosidade destacou-se como predominantemente alta no verão, entretanto foi bem variada no inverno entre as familias de cores e confirmou que as neutras mais escuras são a preferência nos lançamentos dessa estação.

6. Observamos uma forte presença de cores com alta saturação em todos os lançamentos das semanas de moda independentemente da estação ser fria ou quente.

Essas conclusões do monitoramento apontam uma coerência nos lançamentos de moda tanto de São Paulo quanto do Rio de Janeiro: as cores quentes são as preferidas, colocando por terra a crença de que azuis, verdes e violetas são típicas das estações mais frias nessas cidades e referência para todo o pais. Confirmamos, também, a impressão de que, no inverno, o preto é unanimidade nas vestimentas femininas, mesmo que alguns criadores o utilizem em menor proporção do que outros.

Com este artigo pretendemos, além de contribuir para o registro das cartelas lançadas a cada estação durante o periodo desta pesquisa, divulgar a análise pontual das cores predominantes. Esperamos desta forma ajudar os profissionais e as empresas do setor, os professores e alunos de moda a visualizarem como as escolhas de determinadas cores pelos criadores formam uma consistência, tornando-se marcos sinalizadores de cada lançamento de moda.

Este projeto de pesquisa Monitoramento de Cor recebeu Menção Honrosa durante o XXII Seminário de Iniciação Científica da Universidade Federal de Juiz de Fora (MG) no ano de 2016. A sua apresentação, assim como parte do registro de cores e a construção dos mapeamentos, foram feitos com a colaboração de bolsistas de iniciação científica e participação voluntária de alunos. 


\section{REFERÊNCIAS}

ARAÚJO, Mônica de Queiroz Fernandes. A cor incorporada ao ensino de projeto. Rio de Janeiro: UFRJ/FAU, 2006. Xi, 154 f. : il. Tese (Doutorado) - Faculdade de Arquitetura e Urbanismo - Programa de Pós-Graduação em Arquitetura, UFRJ, 2006.

BACK, Suzana. Pesquisa de tendências: um modelo de referência para pesquisa prospectiva. 2008. Dissertação (Mestrado em Engenharia de Produção) - Programa de Pós-Graduação em Engenharia de Produção, UFSC, Florianópolis.

BAUDRILLARD, Jean. 0 sistema dos objetos. São Paulo: Perspectiva, 2012.

BAUER, Martin W.; GASKELL, George. Pesquisa qualitativa com texto, imagem e som: um manual prático. Rio de Janeiro: Editora Vozes, 2007.

CALDAS, Dario. Observatório de sinais: teoria e prática da pesquisa de tendências. Rio de Janeiro: SENAC, 2004.

DOUGLAS, Mary; ISHERWOOD, Baron. 0 mundo dos bens: para uma antropologia do consumo. Rio de Janeiro: UFRJ, 2004. (Col. Etnologia).

GOETHE, Johann Wolfgang von. Doutrina das cores. São Paulo: Nova Alexandria, 1993.

KANDINSKY, Wassily. Do espiritual na arte e na pintura em particular. São Paulo: Martins Fontes, 1996.

LAMBERT, Patricia. Controlling color. A practical introduction for designers and artists. Hong Kong: Everbest Printing Company Ltd, 1991.

NEDER, Mônica. A customização da pesquisa de moda: um método para cada tipo de empresa. Disponivel em: <http://www.coloquiomoda.com.br/anais_ant/anais/9-Coloquio-de-Moda_2013/ARTIGOS-DE-GT/ Artigo-GT-Design-e-Processos-de-Producao-em-Moda/A-customizacao-da-pesquisa-de-moda-ummetodo-para-cada-tipo-de-empresa.pdf>. Acesso em: 17 ago. 2016.

RHEINGANTZ, Paulo A. et al. Observando a qualidade do lugar: procedimentos para a avaliação pósocupação. Rio de Janeiro: Faculdade de Arquitetura e Urbanismo - Pós-Graduação em Arquitetura, UFR, 2009.

SANTOS, Janiene. Sobre tendências e o espírito do tempo. São Paulo: Estação da Letras e Cores, 2013.

SILVA, Anielson. Pesquisa qualitativa em estudos organizacionais: paradigmas, estratégias e métodos. São Paulo: Saraiva, 2006. 